\title{
Stator Current and Rotor Flux Ripples Reduction of DTC DFIG Drive Using FSTSMC Algorithm
}

\author{
Habib Benbouhenni \\ * Laboratoire d'Automatique et d'Analyse des Systèmes (LAAS), Departement de Génie Electrique, Ecole Nationale \\ Polytechnique d'Oran Maurice Audin, Oran, Algeria. \\ (habib0264@gmail.com ) \\ *Corresponding Author; Habib Benbouhenni, BP: 50B Ouled Fares Chlef Algeria, Tel: +213663956329, \\ habib0264@gmail.com
}

Received: 18.10.2019 Accepted:14.12.2019

\begin{abstract}
Over the past years, many kinds of control techniques are proposed for DFIG drives. Among them, the DTC control scheme has gained more importance due to simple control schemes and fast dynamic response. However, it has the disadvantage of high ripples in stator current, rotor flux, torque, and slow response because of hysteresis controllers in torque and rotor flux loop. To improve the performance of direct torque control technique and to minimize the rotor flux and stator current ripples, DTC strategy based fuzzy super-twisting sliding mode controllers (FSTSMC) is proposed in this work. The simulation is carried out using Matlab software and compares the DTC strategy with proportional-integral (PI) controllers and the proposed control scheme is implemented and simulated results are shown.
\end{abstract}

Keywords: DFIG, FSTSMC, DTC, PI.

Nomenclatu
DTC
IM
DFIG
FSTSMC
controller
PI
ANN
FL
SVPWM
SOCSM
THD

Direct torque control

Induction motor

Doubly fed induction generator

Fuzzy super-twisting sliding mode

Proportional integral

Artificial neural network

Fuzzy logic

Space vector pulse width modulation

Second order continuous sliding mode

Total harmonic distortion

\section{Introduction}

In the DTC control scheme of an IM, the command technique is based on the selection of appropriate stator voltage vectors to maintain the torque and flux within their hysteresis comparator bands. The basic principle of the DTC control scheme was proposed by Depenbrock and Takahashi in 1985 [1]. However, the DTC strategy has many advantages, the simplest structure, the fast dynamic response, reliability, and lower parameter dependency, but it has some drawbacks, such as the flux and electromagnetic torque ripples. In [2], the author proposed a novel DTC strategy based on FL and ANNs controllers to control flux and torque of IM drive. In [3], a modified DTC control scheme which can minimize both rotor flux and torque linkage ripples has been proposed for a DFIG by using SOCSM regulators. In [4], the modified DTC method which is based on the SVPWM technique and PI controllers, has been proposed. In [5], DTC strategy based on a sliding mode controller to command DFIG has been proposed.

The main objective of this work is the studying of the DTC strategy with proportional-integral (PI) controllers (DTC-PI) and DTC control scheme with fuzzy logic super-twisting sliding mode controllers (FSTSMC) to the DFIG therefore; our work is structured as follows:

The first part is devoted to the DTC technique based on the PI controllers, this strategy is easy to implement and simple structure. But, this technique gives more THD of stator voltage/current of DFIG.

In the second part, we present a DTC control scheme based on the FSTSMC algorithm to reduce the THD of stator current and rotor flux ripple. Finally, we presented a simulation of DTC-PI and proposed control scheme by using Matlab/Simulink software.

\section{DPC with PI controllers}

The DTC strategy is a simple and alternative approach control formulation that does not require decomposition into symmetrical components, the DTC strategy has been proved 
to be preponderant for DFIGs due to the simple implementation [6]. The DTC goal is to regulate the rotor flux and electromagnetic torque of the DFIG-based WTSs. However, the DTC strategies obtain fast response time and less dependence on DFIG parameters. On the other hand, the model mathematical of DFIG is detailed in [7-9].

In DTC control, it's the rotor flux and the electromagnetic torque which are directly controlled by using two PI controllers and two-level SVPWM strategy. The DTC, which is designed to regulate torque and rotor flux of the DFIG, is shown in Fig. 1[10].

$$
\begin{aligned}
\varphi_{r \alpha} & =\frac{M}{L_{s}} \varphi_{r}+\sigma L_{r} I_{r \alpha} \\
\varphi_{r \beta} & =\sigma L_{r} I_{r \beta}
\end{aligned}
$$

Where :

$$
\sigma=-\frac{M^{2}}{L_{r} L_{s}}+1
$$

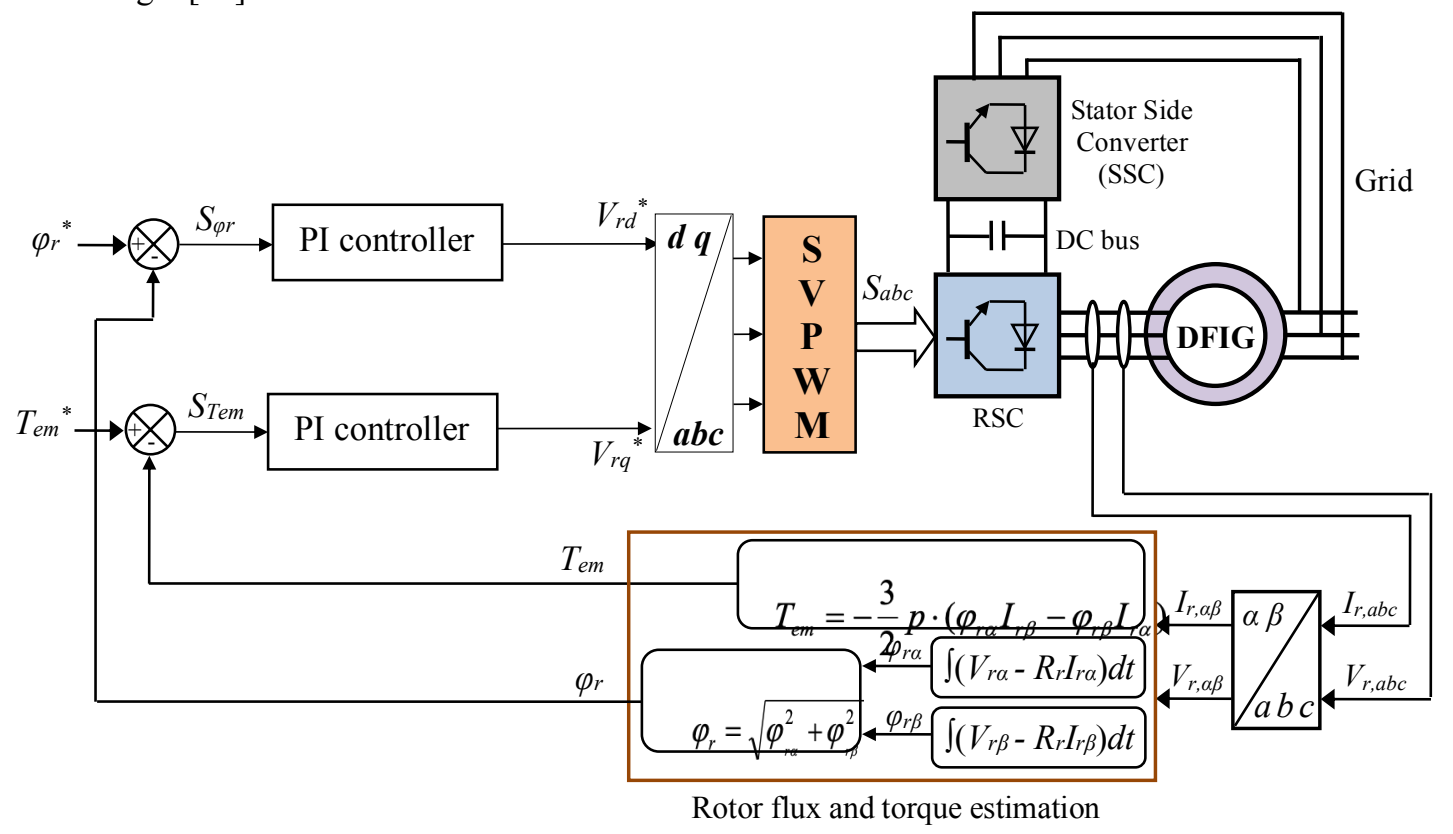

Fig.1 DTC-PI strategy.

The magnitude of the flux, which can be estimated by:

$$
\begin{aligned}
\varphi_{r \alpha} & =\int_{0}^{t}\left(-R_{r} I_{r \alpha}+V_{r \alpha}\right) d t \\
\varphi_{r \beta} & =\int_{0}^{t}\left(-R_{r} I_{r \beta}+V_{r \beta}\right) d t
\end{aligned}
$$

Where $: V_{\text {r } \alpha}$ is the rotor voltage linkage of $\alpha$-axis.

$\mathrm{V}_{\mathrm{r} \beta}$ : is the rotor voltage linkage of $\beta$-axis.

$\varphi_{\mathrm{r} \beta}:$ is the rotor flux linkage of $\beta$-axis.

$\varphi_{\mathrm{r} \alpha}:$ is the rotor flux linkage of $\alpha$-axis.

$I_{r \alpha}:$ is the rotor current linkage of $\alpha$-axis.

$\mathrm{I}_{\mathrm{r} \beta}:$ is the rotor current linkage of $\beta$-axis.

The rotor flux amplitude is given by:

$$
\varphi_{r}=\sqrt{\varphi_{r \beta}^{2}+\varphi_{r \alpha}^{2}}
$$

Where $: \varphi_{\mathrm{r}}$ is the rotor flux.

The rotor flux angle is calculated by :

$$
\theta_{r}=\operatorname{arctg}\left(\frac{\varphi_{r} \beta}{\varphi_{r \alpha}}\right)
$$

\section{DTC with FSTSMC algorithm}

To improve the DTC with PI controllers performances, a complimentary use of the FSTSMC algorithm is proposed. The principle of DTC with the FSTSMC algorithm (DTCFSTSMC) is similar to the DTC-PI control scheme. The difference is using an the FSTSMC algorithm to replace the classical PI controllers.

This proposed strategy reduced torque ripple, rotor flux ripple and THD of stator voltage/current compared to DTCPI control scheme. This proposed strategy is easy to implement and simple structure.

Recently applications of the SMC technique become more convenient in control systems. The SMC technique is popular in more applications. This technique proposed by Utkin in 1977 [11]. Since the robustness is the best advantage of an SMC method, it has been widely employed to control nonlinear systems that have model uncertainty and external disturbance [12, 13].

The STSM algorithm maintains the advantages of the traditional SMC techniques and allows for the elimination of the undesirable phenomena of chattering [14]. The output signal from the controller of this type is comparable with the control signal obtained from linear PI regulators. This algorithm is proposed by Utkin in 1999 [15]. On the other 
hand, this algorithm is easy to implement and simple scheme compared to another classical algorithm.

The control law of the STSMC algorithm can be defined as follows [16]:

$$
\left\{\begin{array}{c}
u=K_{1}|S|^{r} \operatorname{sgn}(S)+u_{1} \\
\frac{d u_{1}}{d t}=K_{2} \operatorname{sgn}(S)
\end{array}\right.
$$

where $K_{1}$ and $K_{2}$ are the coefficients of the proportional and integral parts of the STSMC algorithm, $S$ is the switching function determined for the STSMC algorithm respectively; $r$ is the exponent defined for the STSMC algorithm.

The graphical representation of the control law of the STSMC algorithm is shown in Fig. 2.

$$
\begin{gathered}
\left\{\begin{array}{c}
V_{d r}=K_{1}\left|S_{Q_{r}}\right|^{r} \operatorname{sgn}\left(S_{Q_{r}}\right)+\dot{V}_{d r 1} \\
\cdot \\
V_{d r 1}=K_{2} \operatorname{sgn}\left(S_{Q_{r}}\right)
\end{array}\right. \\
\left\{\begin{array}{c}
V_{q r}=K_{1}\left|S_{T_{e m}}\right|^{r} \operatorname{sgn}\left(S_{T_{e m}}\right)+V_{q r 1} \\
\frac{d V_{q r 1}}{d t}=K_{2} \operatorname{sgn}\left(S_{T_{e m}}\right)
\end{array}\right.
\end{gathered}
$$

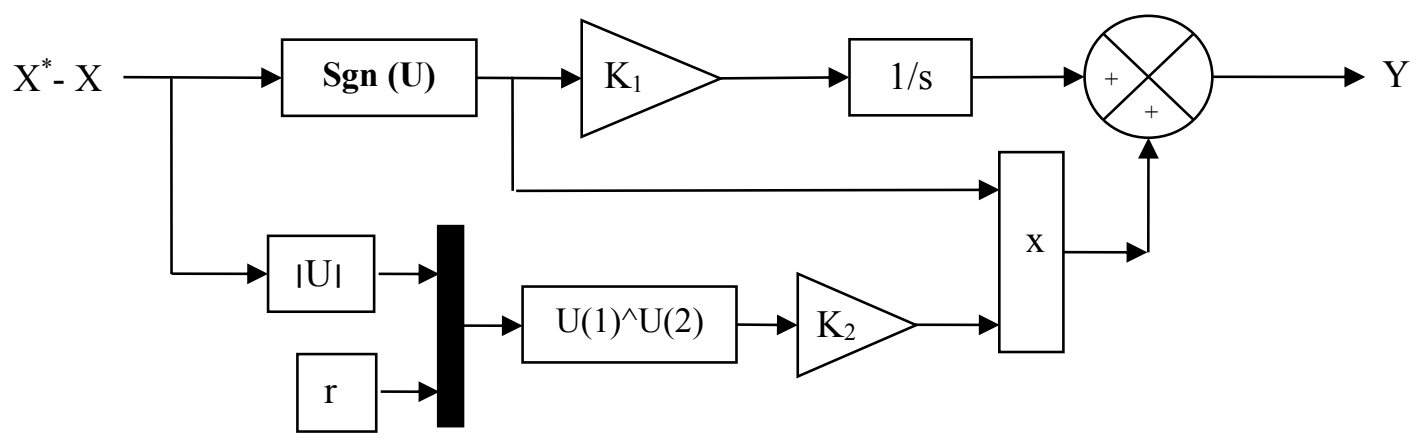

Fig. 2. Graphical representation of the control law of the STSM controller.

Where the rotor flux magnitude error $S_{Q r}=Q r_{r e f}-Q r$ and the torque error $S_{T e m}=T e m_{r e f}-T e m$, and the constant gains $k_{1}$ and $k_{2}$ must check the stability conditions.

The proposed STSMC algorithm, which is designed to regulate the torque and rotor flux of the DFIG is shown in Fig. 3.

The original contribution of this work is the application of the STSMC algorithm in the DTC control scheme with a three-phase DFIG and simulation investigation of this novel control scheme.

The FSTSMC algorithms are a modification of the traditional STSMC algorithms, where the switching controller term $\operatorname{sgn}(U)$, has been replaced by a fuzzy logic controller as shown in Fig. 4. Both of them do not need advanced mathematical models.

The FLC method is proposed by Zadeh in 1965 [17]. This control technique is widely used in many areas. Traditionally, FL variables have been adjusted by expert knowledge [18]. The block diagram of the FLC based $\operatorname{sign}(\mathrm{U})$ is shown in Fig. 5. The FL rules for the proposed command scheme are given in Table 1 [19-21]. The membership function definition is shown in Fig. 6.

The STSMC torque and rotor flux regulators are designed to respectively change the $d$ and $q$-axis voltages as in equations

\begin{tabular}{|c|c|c|c|c|c|c|c|}
\hline e & \multirow[t]{2}{*}{ NB } & \multirow[t]{2}{*}{ NM } & \multirow[t]{2}{*}{ NS } & \multirow[t]{2}{*}{$\mathbf{E Z}$} & \multirow[t]{2}{*}{ PS } & \multirow[t]{2}{*}{$\mathbf{P M}$} & \multirow[t]{2}{*}{ PB } \\
\hline$\Delta \mathbf{e}$ & & & & & & & \\
\hline NS & NB & NB & NM & NS & EZ & PS & $\mathrm{PM}$ \\
\hline NM & NB & NB & NB & NM & $\mathrm{NS}$ & EZ & PS \\
\hline NB & NB & NB & NB & NB & NM & $\mathrm{NS}$ & EZ \\
\hline PS & NM & NS & EZ & PS & PM & PB & PB \\
\hline EZ & $\mathrm{NB}$ & NM & $\mathrm{NS}$ & EZ & PS & $\mathrm{PM}$ & $\mathrm{PB}$ \\
\hline PB & EZ & PS & PM & PB & PB & PB & PB \\
\hline $\mathbf{P M}$ & NS & $\mathrm{EZ}$ & PS & PM & PB & PB & PB \\
\hline
\end{tabular}
(9) and (10) :
Table 1. Fuzzy ruls

The DTC control scheme of three-phase DFIG with the application of the FSTSMC algorithm is shown in Fig. 7. In this strategy, the torque, the magnitude of the rotor flux vector are controlled by the FSTSMC algorithm. The DTC with FSTSMC algorithms goal is to reduces the rotor flux ripple, THD of current and torque ripple of the DFIG-based wind turbines. 

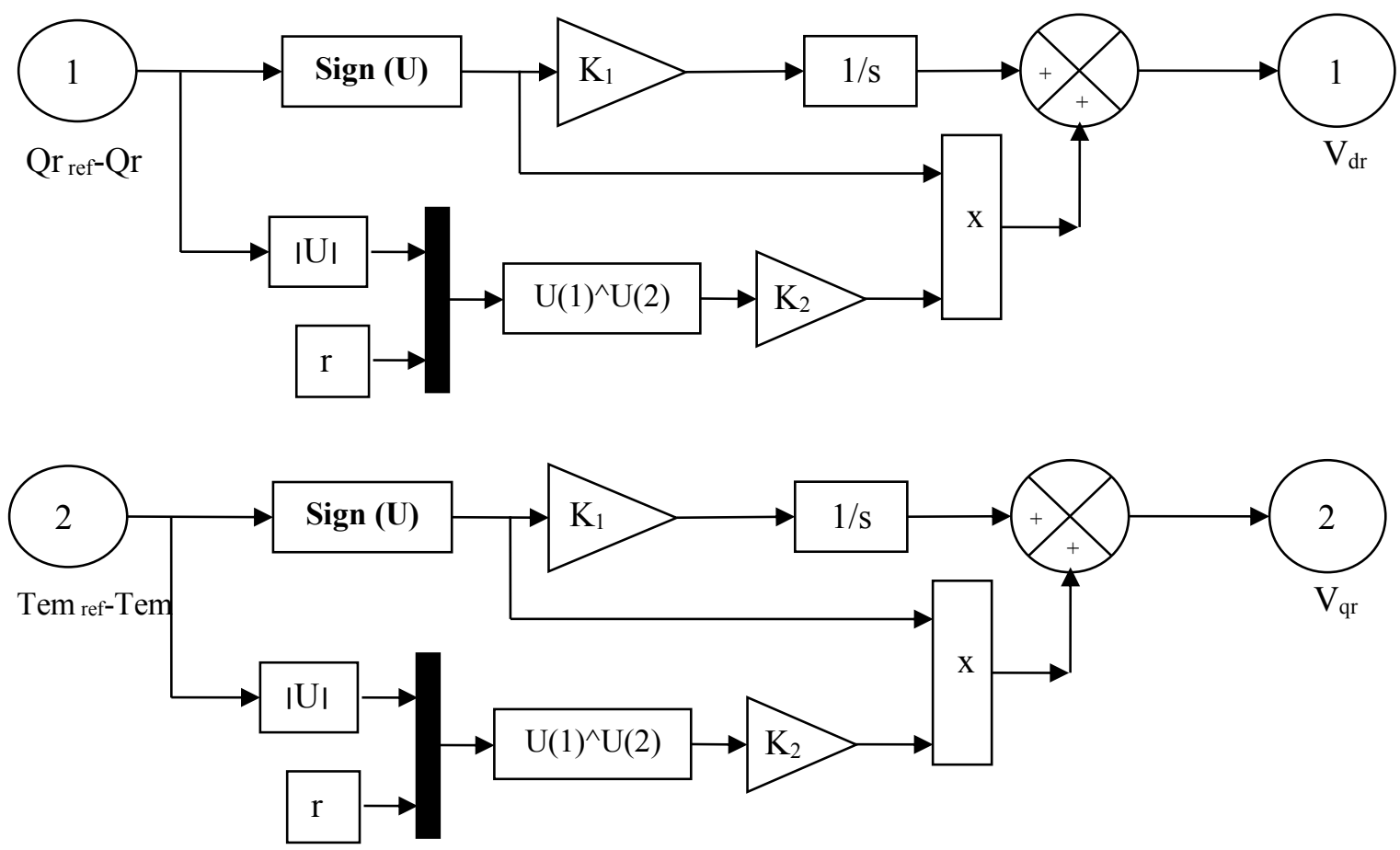

Fig. 3 Block diagram of STSMC algorithm.
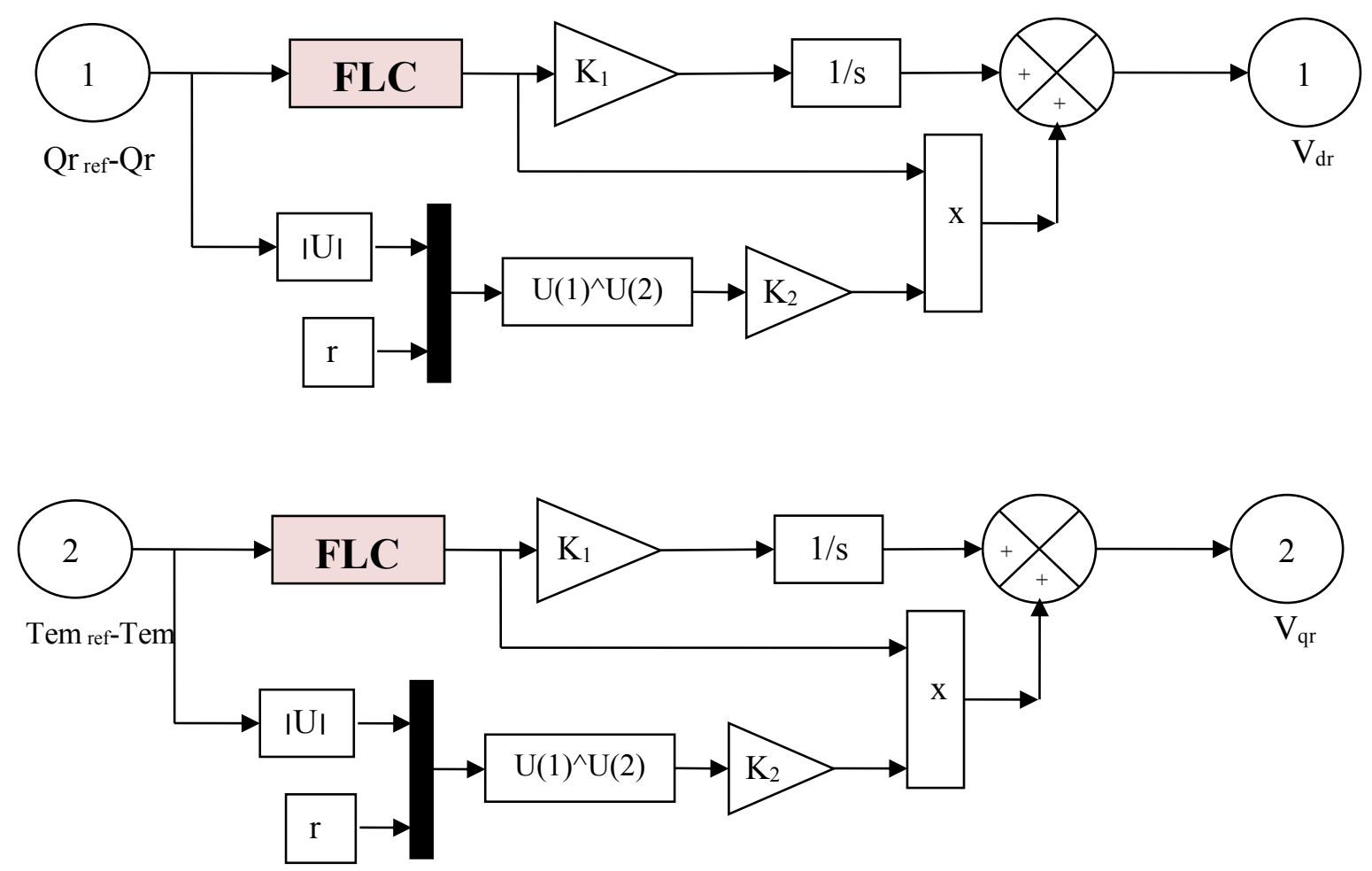

Fig. 4 Block diagram of FSTSMC algorithm. 


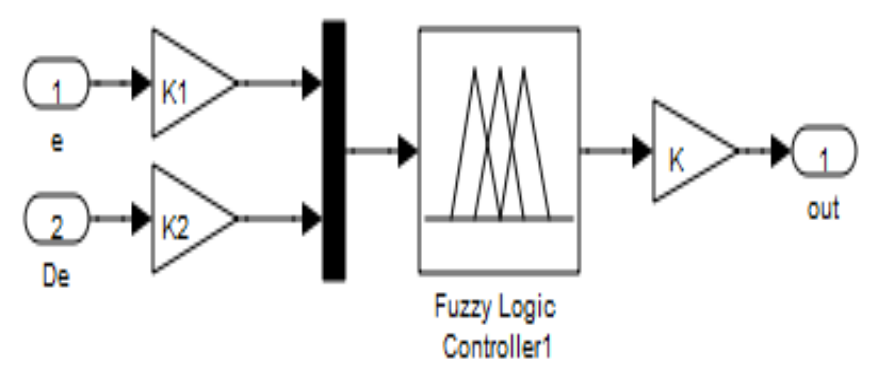

Fig. 5 FLC controller.

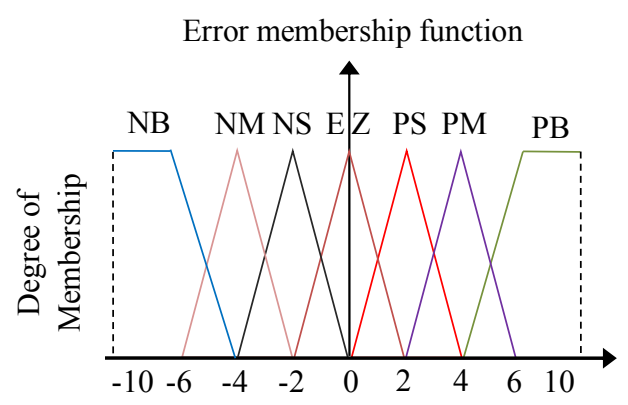

a) Error

Change in error membership function

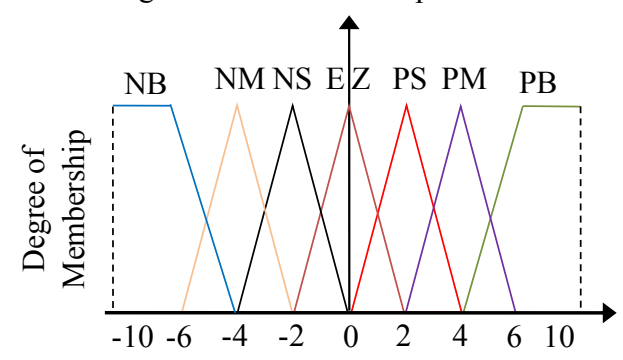

b) Change in error

\section{Simulation results}

The simulation results of DTC-FSTSMC strategy of DFIG are compared with DTC-PI strategy. The performance analysis is done with flux, harmonic distortion of stator current and torque. The DFIG used in this case study is a $1.5 \mathrm{MW}, 2$ poles, $380 / 696 \mathrm{~V}, 50 \mathrm{~Hz}, \mathrm{Rr}=0.021 \Omega$, fr $=0.0024$ $\mathrm{Nm} / \mathrm{s}, \mathrm{Rs}=0.012 \Omega, \mathrm{Lr}=0.0136 \mathrm{H}, \mathrm{J}=1000 \mathrm{~kg} \cdot \mathrm{m} 2, \mathrm{Ls}=$ $0.0137 \mathrm{H}$ and $\mathrm{Lm}=0.0135 \mathrm{H}$.

\section{A. Reference tracking test (RTT)}

Figs. 8-9 shows the THD of the current of the DFIG for DTC with PI controllers and DTC-FSTSMC strategy one respectively. It can be clearly observed that the THD is minimized for DTC-FSTSMC when compared to the DTCPI technique (See Table 2).

For the DTC-FSTSMC and DTC-PI strategy, the rotor flux and torque tracks almost perfectly their reference values (see Figs. 10-11).

Rotor flux response comparing curves are shown in Fig. 14. See figure the rotor flux ripple is significantly minimized when the DTC-FSTSMC technique is in use.

Fig. 12 and Fig. 15 shows the current responses of both the DTC-PI and DTC-FSTSMC control scheme. It is found that the proposed DTC-FSTSMC exhibits smooth response and lesser ripple in stator current as compared to the DTC-PI method.

Torque response comparing curves are shown in Fig. 13. See figure the electromagnetic torque ripple is significantly minimized when the DTC with FSTSMC algorithm is in use.

Fig. 6 Membership functions.

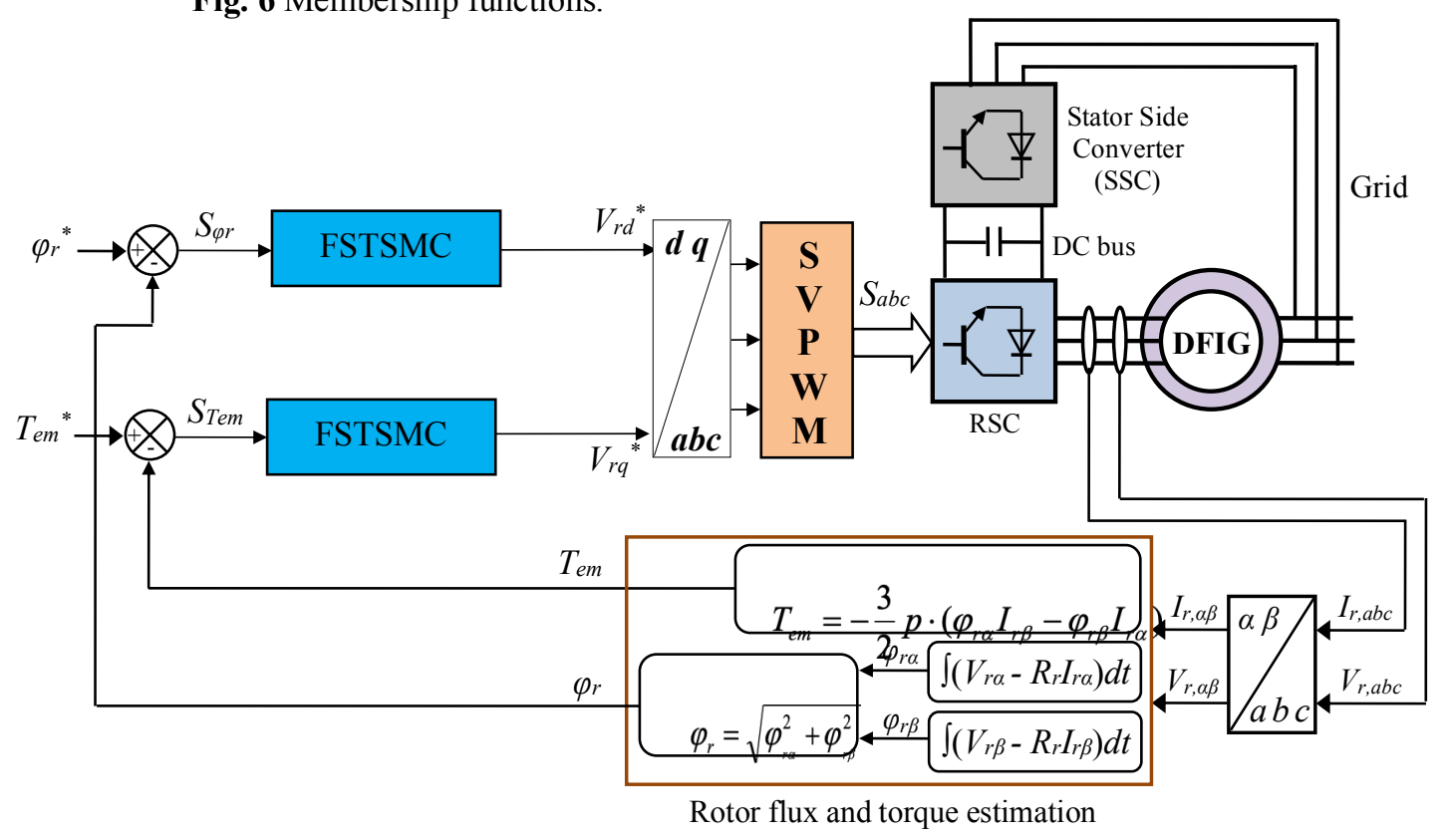

Fig. 7 DTC system of three-phase DFIG with the application of FSTSMC algorithm. 
INTERNATIONAL JOURNAL OF SMART GRID

Habib Benbouhenni, Vol.3, No.4, December 2019

Table 2. Comparative analysis of THD value (RTT)

\begin{tabular}{|l|c|c|}
\cline { 2 - 3 } \multicolumn{1}{c|}{} & \multicolumn{2}{c|}{ THD (\%) } \\
\cline { 2 - 3 } \multicolumn{1}{c|}{} & DTC-PI & $\begin{array}{c}\text { DTC- } \\
\text { FSTSMC }\end{array}$ \\
\hline Stator current & 0.65 & $\mathbf{0 . 2 5}$ \\
\hline
\end{tabular}
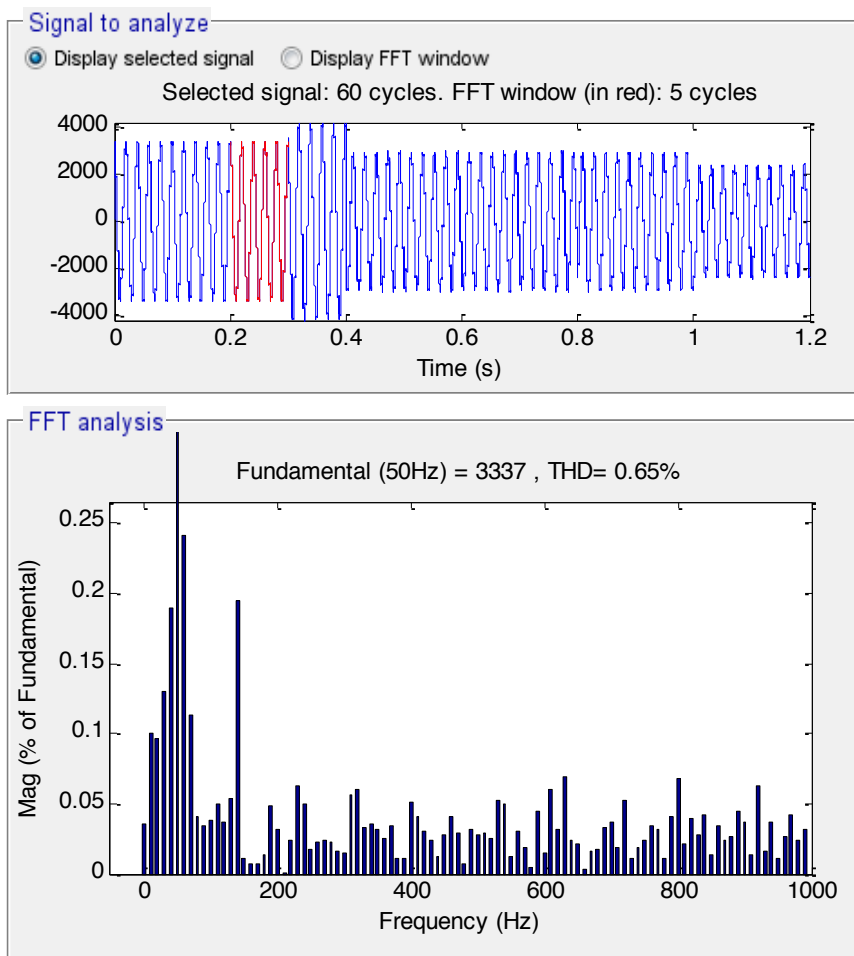

Fig. 8 THD of stator current (DTC-PI).
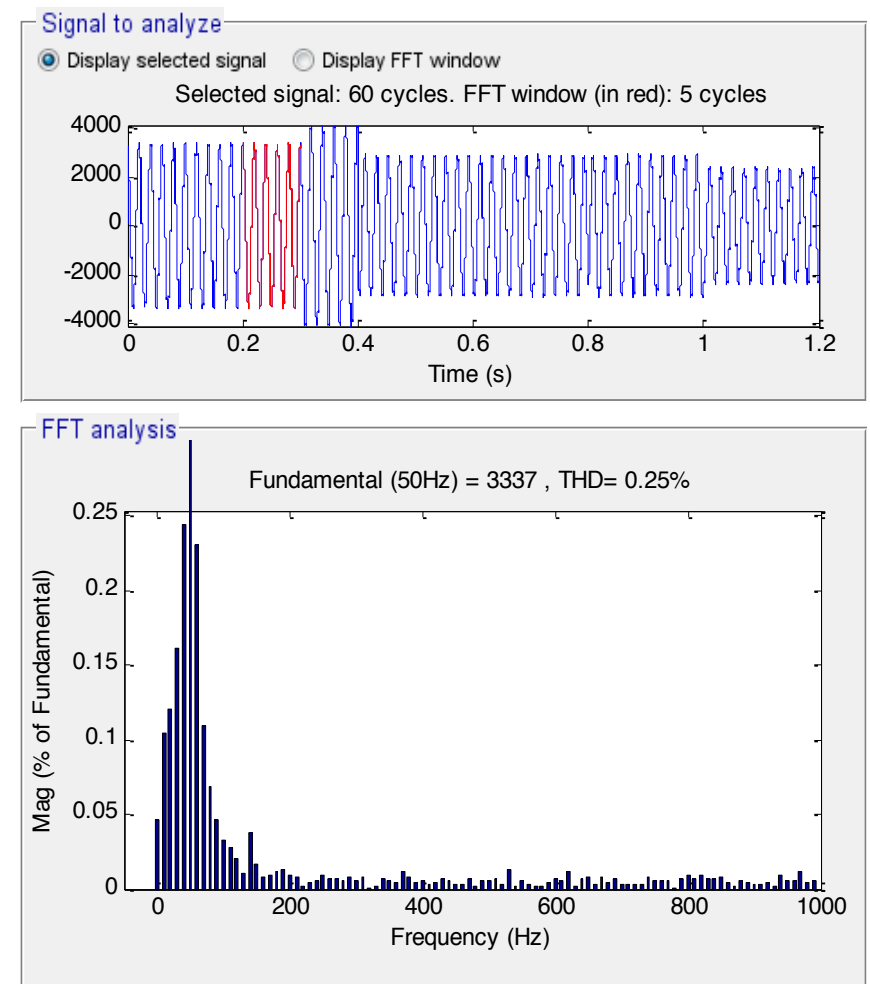

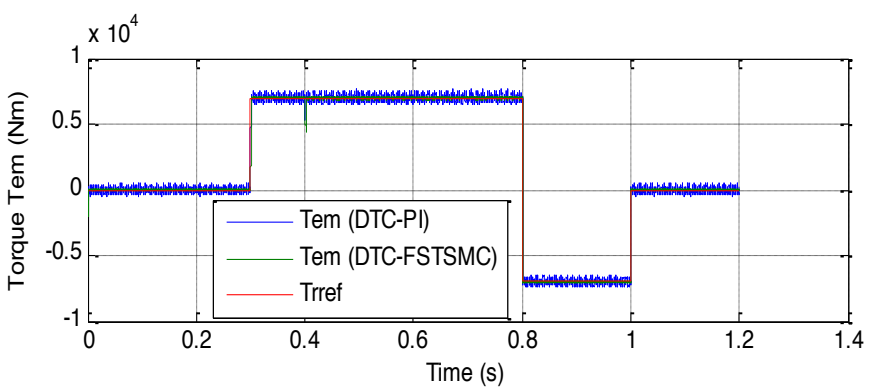

Fig.10 Torque (RTT).

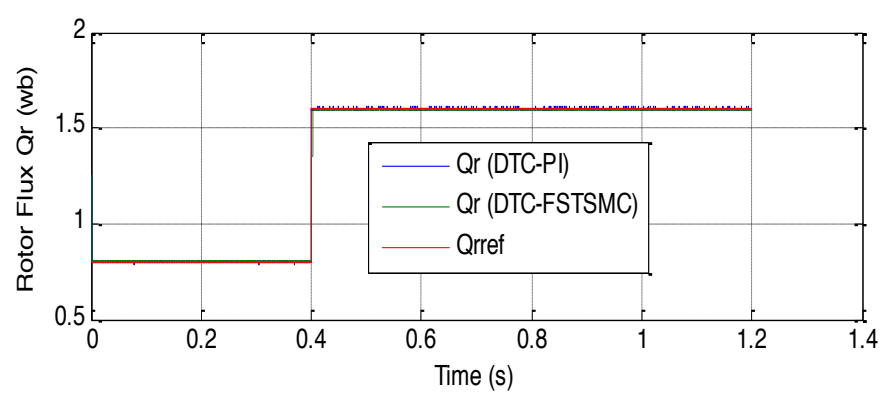

Fig.11 Rotor flux (RTT).

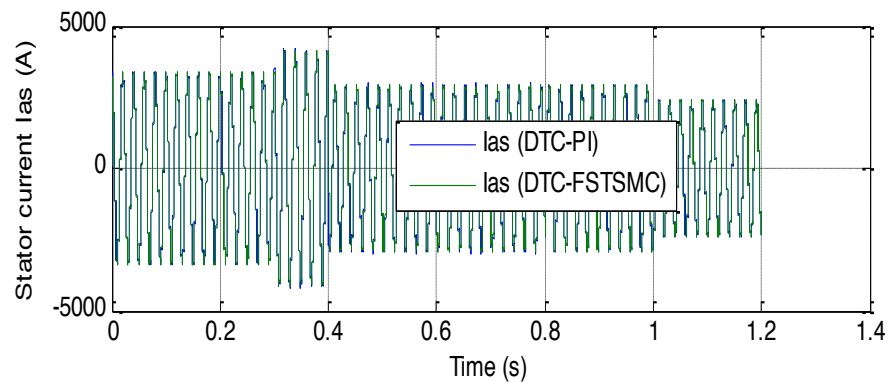

Fig.12 Stator current (RTT).

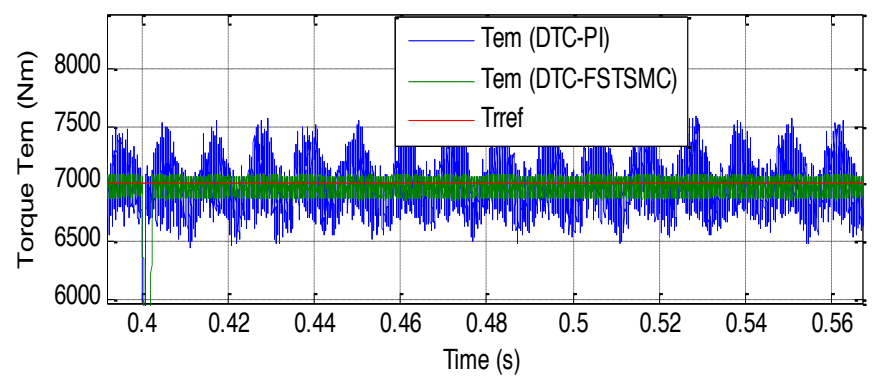

Fig. 13 Zoom in the torque (RTT).

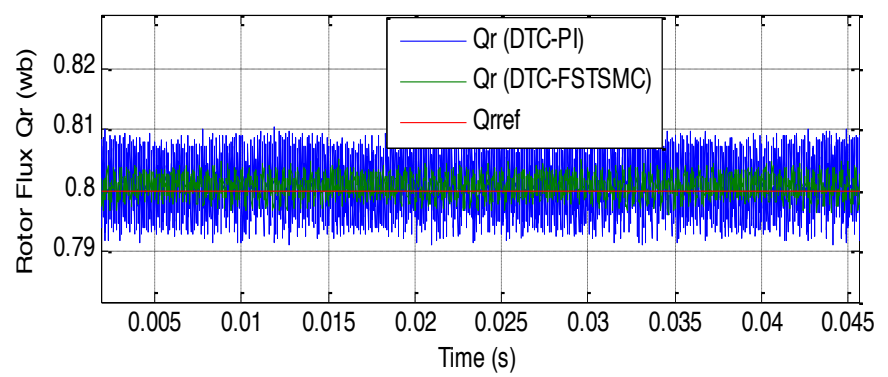

Fig. 14 Zoom in the rotor flux (RTT).

Fig. 9 THD of stator current (DTC-FSTSMC). 


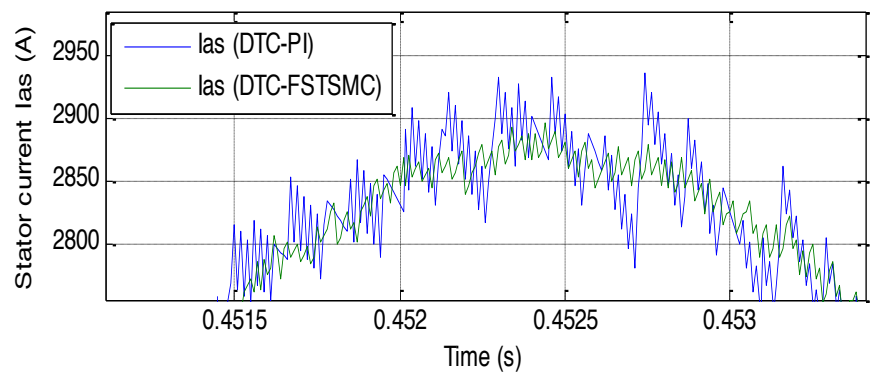

Fig. 15 Zoom in the stator current (RTT).

\section{B.Robustness Test (RT)}

In order to test the robustness of the proposed strategies, machine parameters have been modified: the resistances $R_{s}$ and $R_{r}$ are doubled and the values of the inductances $L_{s}$ and $L_{r}$ are divided by 2. Simulation results are presented in Figs. 16-23. As it's shown by these figures, these variations present a clear effect on stator current, torque and rotor flux and that the effect appears more important for the DTC-PI strategy than that with DTC with FSTSMC algorithm. Thus, it can be concluded that the proposed DTC with FSTSMC algorithm is more robust than the DTC-PI one.
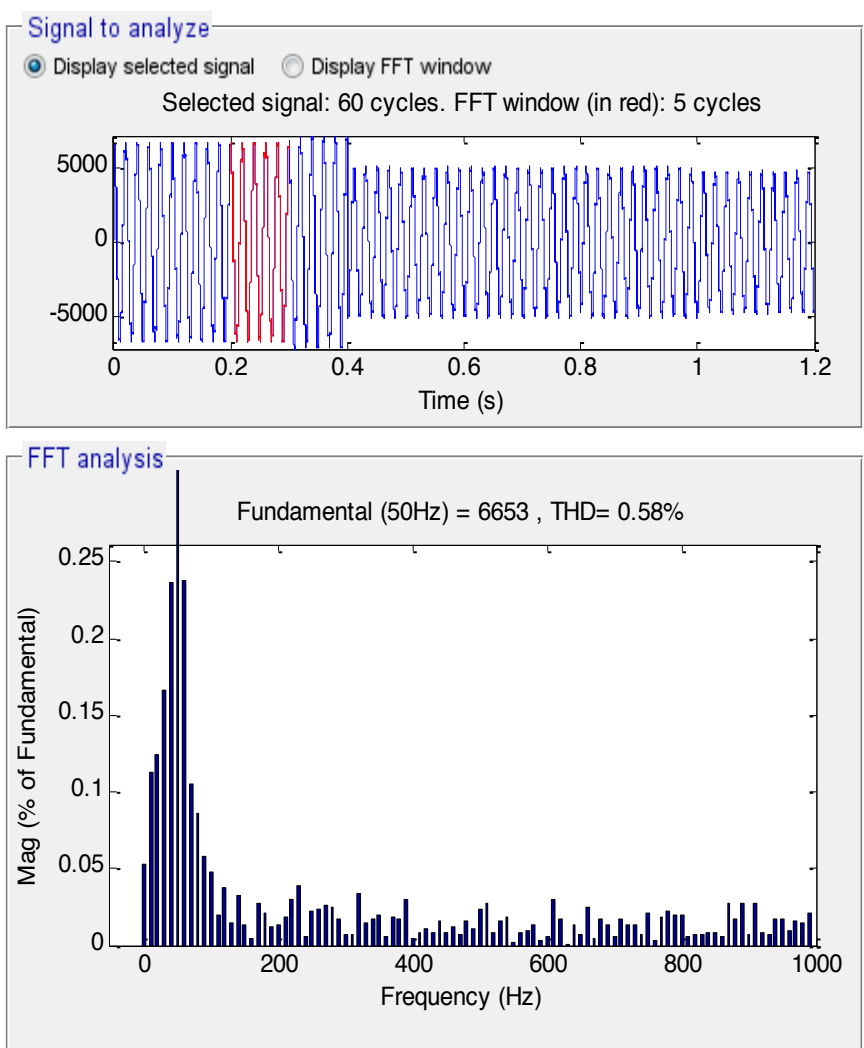

Fig. 16 THD of stator current (DTC-PI)
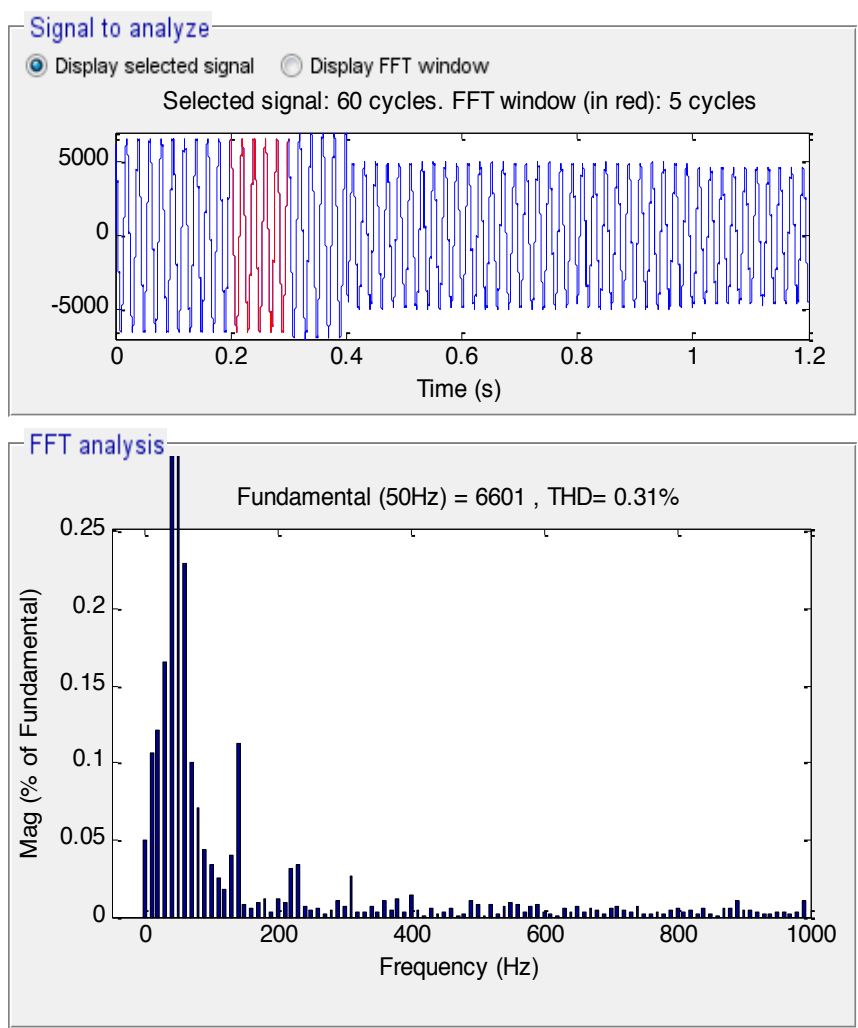

Fig. 17 THD of stator current (DTC-FSTSMC).

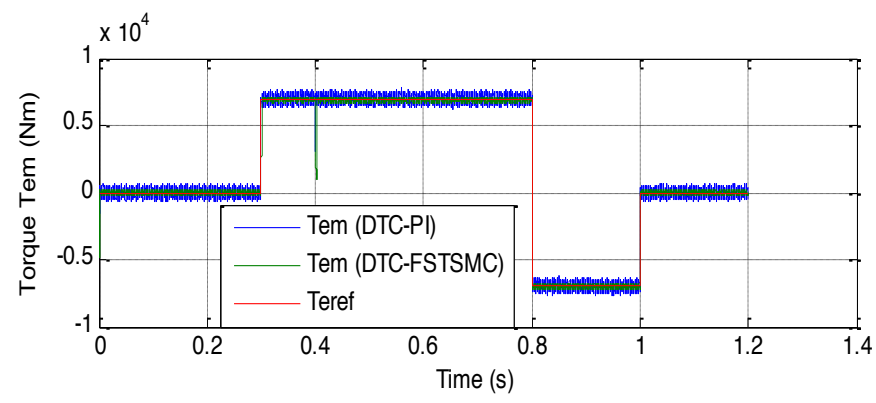

Fig.18 Torque (RT).

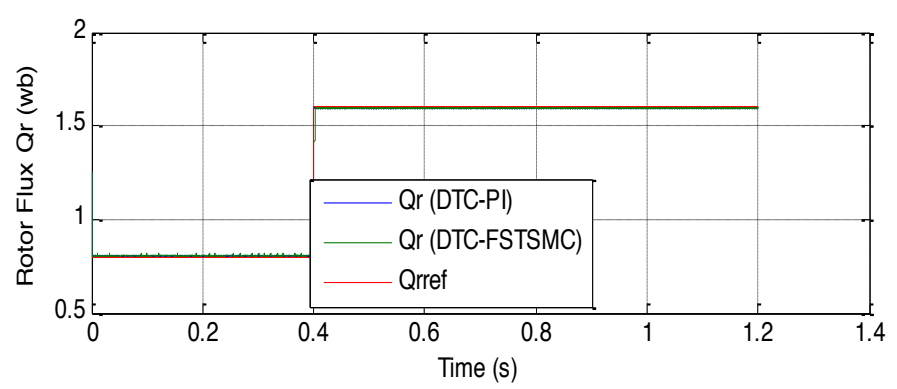

Fig.19 Rotor flux (RT). 


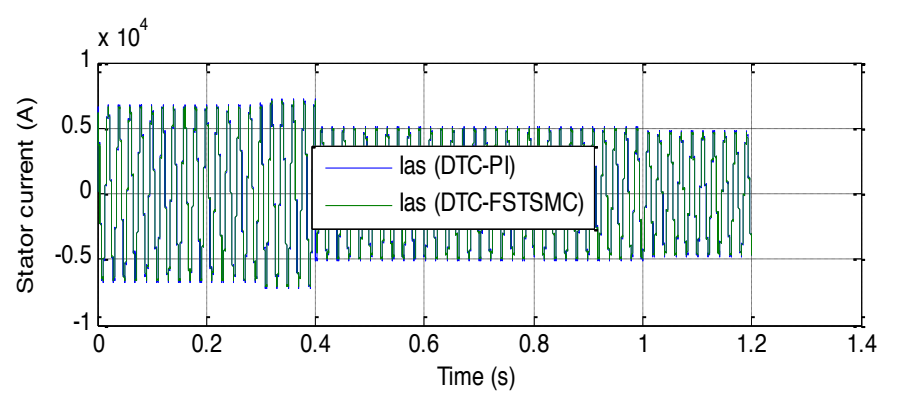

Fig.20 Stator current (RT).

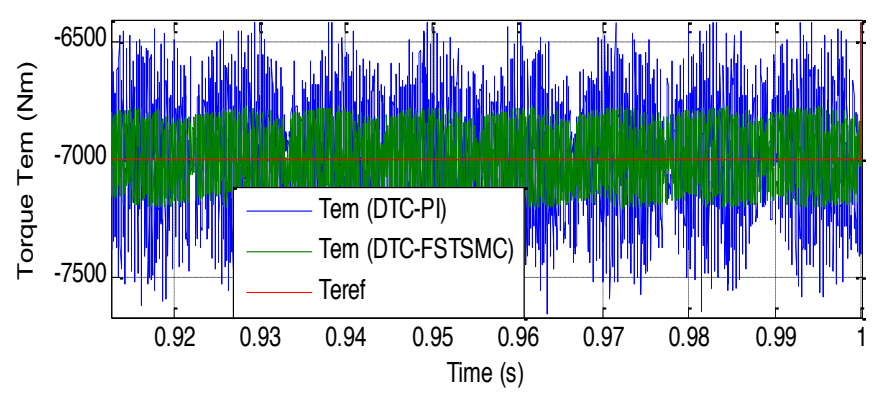

Fig.21 Zoom in the torque (RT).

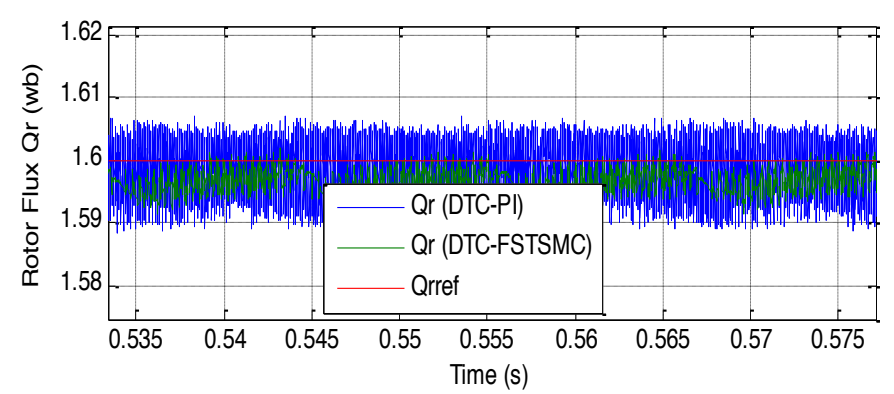

Fig. 22 Zoom in the rotor flux (RT).

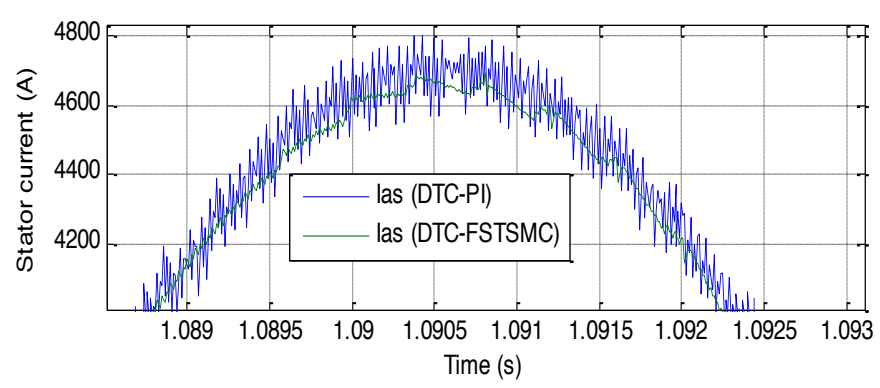

Fig. 23 Zoom in the stator current (RT).

\section{Conclusion}

Based on the FSTSMC algorithm, the DTC strategy is proposed to regulate the electromagnetic torque and flux of the DFIG-based wind turbine. The DTC-FSTSMC technique is easy to implement and a simple control scheme. The torque and rotor flux is controlled by using FSTSMC algorithm. The performance of the proposed command is verified by the computer simulations. The simulation results show that the rotor flux ripple, harmonic distortion of stator current and electromagnetic torque ripple in the DTCFSTSMC control scheme are reduced compared to DTC with PI controllers and even compared with results presented in other recent works such as [3] and [10].

\section{References}

[1] I. Takahashi, T. Naguchi, « A new quick-response and high-efficiency control strategy of an induction motor, 》 IEEE Transactions on Industry Applications, Vol. 5, pp. 820-827, 1986.

[2] H. Benbouhenni, « Seven-level direct torque control of induction motor based on artificial neural networks with regulation speed using fuzzy PI controller, " Iranian Journal of Electrical and Electronic Engineering, Vol. 14, No. 1, pp. 85-94, 2018.

[3] Z. Boudjema, R. Taleb, Y. Djerriri, A. Yahdou, « A novel direct torque control using second order continuous sliding mode of a doubly fed induction generator for a wind energy conversion system, " Turkish Journal of Electrical Engineering \& Computer Sciences, Vol. 25, pp. 965-975, 2017.

[4] M. S. Raj, T. Saravanan, V. Srinivasan, «A modified direct torque control of induction motor using space vector modulation technique, » MiddleEast Journal of Scientific Research, Vol. 20, No. 11, pp.1572-1574, 2014.

[5] S. Z. Chen, N. C. Cheung, K. C. Wong, J. Wu, «Integral Sliding-mode direct torque control of doubly-fed induction generators under unbalanced grid voltage, » IEEE Transaction on Energy Conversion, Vol. 25, No. 2, pp. 356-368, 2010.

[6] S. Gdaim, A. Mtibaa, and M. F. Mimouni, «Direct torque control of induction machine based on intelligent techniques, " International Journal of Computer Applications, Vol. 10, No. 8, pp. 29-35, 2010.

[7] H. Benbouhenni, Z. Boudjema, A. Belaidi, «Neurosecond order sliding mode control of a DFIG supplied by a two-level NSVM inverter for wind turbine system, " Iranian Journal of Electrical \& Electronic Engineering, Vol. 14, No. 4, pp. 362373, 2018.

[8] H. Benbouhenni, «Sliding mode with neural network regulateur for DFIG using two-level NPWM strategy, » Iranian Journal of Electrical \& Electronic Engineering, Vol. 15, No. 3, pp. 411419, 2019.

[9] H. Benbouhenni, Z. Boudjema, A. Belaidi, «Using four-level NSVM technique to improve DVC control of a DFIG based wind turbine systems, » 
Periodica Polytechnica Electrical Engineering and Computer Science, Vol. 63, No. 3, pp. 144-150, 2019.

[10] Z. Boudjema, R. Taleb, A. Yahdou, «A new DTC scheme using second order sliding mode and fuzzy logic of a DFIG for wind turbine system, » International Journal of Advanced Computer Science and Application, Vol. 7, No. 8, pp. 49-56, 2016.

[11] H. Benbouhenni, " Comparative study between NSVM and FSVM strategy for a DFIG-based wind turbine system controlled by neuro-second order sliding mode, " Majlesi Journal of Mechatronic Systems, Vol. 7, No. 1, pp. 33-43, 2018.

[12] H. Benbouhenni, «A comparative study between FSMC and FSOSMC strategy for a DFIG-based wind turbine system,» Majlesi Journal of Mechatronic Systems, Vol. 8, No. 2, 2019.

[13] H. Benbouhenni, Z. Boudjema, A. Belaidi, «A novel matlab/simulink model of DFIG drive using NSMC method with NSVM strategy, » International Journal of Applied Power Engineering (IJAPE), Vol. 8, No. 3, pp. 221-233, 2019.

[14] I. Yaichi, A. Semmah, P. Wira, Y. Djeriri, «Supertwisting sliding mode control of a doubly-fed induction generator based on the svm strategy, » Periodica Polytechnica Electrical Engineering and Computer Science, Vol. 63, No. 3, pp. 178-190, 2019.

[15] J. Listwan, « Application of Super-Twisting Sliding Mode Controllers in Direct Field-Oriented Control System of Six-Phase Induction Motor: Experimental Studies, » Power Electronics and Drives, Vol. 38, No. 1, 2018

[16] S. Tayebi-Haghighi, F. Piltan, J. M. Kim, «Robust Composite High-Order Super-Twisting Sliding Mode Control of Robot Manipulators, " Robotics, Vol. 7, No. 1, 2018.

[17] Y. Guo, H. Long, « Self organizing fuzzy sliding mode controller for the position control of a permanent magnet synchronous motor drive, » Ain Shams Engineering Journal, Vol. 2 , pp. 109-118, 2011.

[18]H. Benbouhenni, Z. Boudjema, A. Belaidi, « Direct vector control of a DFIG supplied by an intelligent SVM inverter for wind turbine system, " Iranian Journal of Electrical and Electronic Engineering, Vol. 15, No. 1, pp. 45-55, 2019.

[19] H. Benbouhenni, Z. Boudjema, A. Belaidi, « Indirect vector control of a DFIG supplied by a twolevel FSVM inverter for wind turbine system, »
Majlesi Journal of Electrical Engineering, Vol. 13, No. 1, 2019.

[20] H. Benbouhenni, Z. Boudjema, A. Belaidi, «Using three-level fuzzy space vector modulation method to improve indirect vector control strategy of a DFIG based wind energy conversion systems, » International Journal of Smart Grid, Vol. 2, No. 3, 2018.

[21] H. Benbouhenni, " Comparative study between NSVM and FSVM strategy for a DFIG-based wind turbine system controlled by neuro-second order sliding mode, » Majlesi Journal of Mechatronic Systems, Vol. 7, No. 1, pp. 33-43, 2018. 